\title{
NOWE STANOWISKO PLANTAGO MARITIMA (PLANTAGINACEAE) W WIELKOPOLSCE
}

\author{
A NEW LOCALITY OF PLANTAGO MARITIMA (PLANTAGINACEAE) \\ IN THE WIELKOPOLSKA REGION (W POLAND)
}

\begin{abstract}
Aneta Czarna
A. Czarna, Katedra Botaniki, Uniwersytet Przyrodniczy w Poznaniu, ul. Wojska Polskiego 71 C, 60-625 Poznań, Poland, e-mail: czarna@up.poznan.pl
\end{abstract}

\begin{abstract}
Plantago maritima is obligatory halophyte vulnerable (VU) in Poland. The new local population was found on 20 August 2013. It was located on a roadside about 4 km from Nowogród Bobrzański, beside the road to Zielona Góra. It was composed of two flowering clumps, which fruited later (22 October 2013).
\end{abstract}

KeY WoRDs: vascular flora, protected species, Plantago maritima, exposed species, Wielkopolska region

W Polsce występują dwa gatunki z rodzaju Plantago, które są związane ze słonymi łąkami - P. maritima L. (babka nadmorska) i P. coronopus L. (babka pierzasta). Plantago maritima jest byliną, $\mathrm{z}$ torebkami dwunasiennymi, a $P$. coronopus to bylina roczna lub dwuletnia, o torebce 3- lub 4-nasiennej. Babka nadmorska ma równowąskie i mięsiste liście, które w nasadzie są pochwiaste, całobrzegie, rzadziej bardzo słabo i odlegle ząbkowane (SzAFer i in. 1986). Wykształca nasiona o długości od 1,6 do 2,00 mm i szerokości od 0,69 do $1,0 \mathrm{~mm}$.

Plantago maritima jest halofitem obligatoryjnym. W Europie jest związana głównie $z$ północnym, zachodnim i południowym wybrzeżem, z wyjątkiem obszaru Portugalii, występuje też na nielicznych stanowiskach śródlądowych. Znana jest z wyspowych stanowisk w północno-zachodniej Afryce i południowo-zachodniej Azji (Meusel \& Jäger 1992, Sotek 2014).

Babka nadmorska występuje na łąkach zasolonych wodami morskimi lub słonymi wodami podziemnymi. W Polsce związana głównie z wybrzeżem Bałtyku (Sotek i in. 2014). Z naszego kraju podano dotychczas także trzy stanowiska śródlądowe. Jedno stwierdzono w Ciechocinku (AsCHERSON \& GRAEBNER 1898-1902), drugie na Dolnym Śląsku (FIEK 1881), a trzecie w regionie Dołów Jasielsko-Sanockich (JAźWA \& PiĄTEK 2015).

W Polsce P. maritima została wpisana na „czerwoną listę” z kategorią VU - gatunek narażony
(KaźmierczaKowa i in. 2016), a także uwzględniona w „Polskiej czerwonej księdze roślin” (KaźmierczAKOWA i in. 2016), również z kategorią VU. Należy do gatunków podlegających całkowitej ochronie w Polsce (RozPORZĄDZENIE... 2014).

Nowe stanowisko P. maritima, odnalezione w 2013 roku, znajdowało się około $4 \mathrm{~km}$ na wschód za miejscowością Nowogród Bobrzański (gmina Nowogród Bobrzański, powiat zielonogórski, województwo lubuskie, kwadrat ATPOL AD67). Usytuowane było na poboczu szosy przebiegającej przez bory sosnowe. Populacja gatunku składała się z dwóch kwitnących (20.08.2013, ryc. 1), a później owocujących kęp (22.10.2013). Skład florystyczny płatu z udziałem P. maritima przedstawia poniższe zdjęcie fitosocjologiczne. Warto zauważyć obecność w fitocenozie kolejnego halofita - Puccinellia distans. Trawa ta rozprzestrzenia się wzdłuż ulic i szos na skutek posypywania ich $\mathrm{w}$ zimie solą.

Lolio-Polygonetum puccinellietosum distantis $\mathrm{R}$. Tx. 1950, data wykonania zdjęcia: 20.08.2013 r.; powierzchnia: $5 \mathrm{~m}^{2}$; pokrycie warstwy c: $30 \%$; liczba gatunków: 16; Polygonum aviculare 2.3, Lolium perenne 1.1, Achillea millefolium +, Arrhenatherum elatius,+ Artemisia vulgaris r, Brassica napus r, Digitaria ischaemum + , Plantago lanceolata + , Plantago major + , Puccinellia distans + , Rumex acetosella + , Taraxacum officinale + , Fagopyrum esculentum r, Matricaria maritima subsp. inodora r, Plantago maritima $\mathbf{r}$, Sinapis arvensis $\mathrm{r}$. 


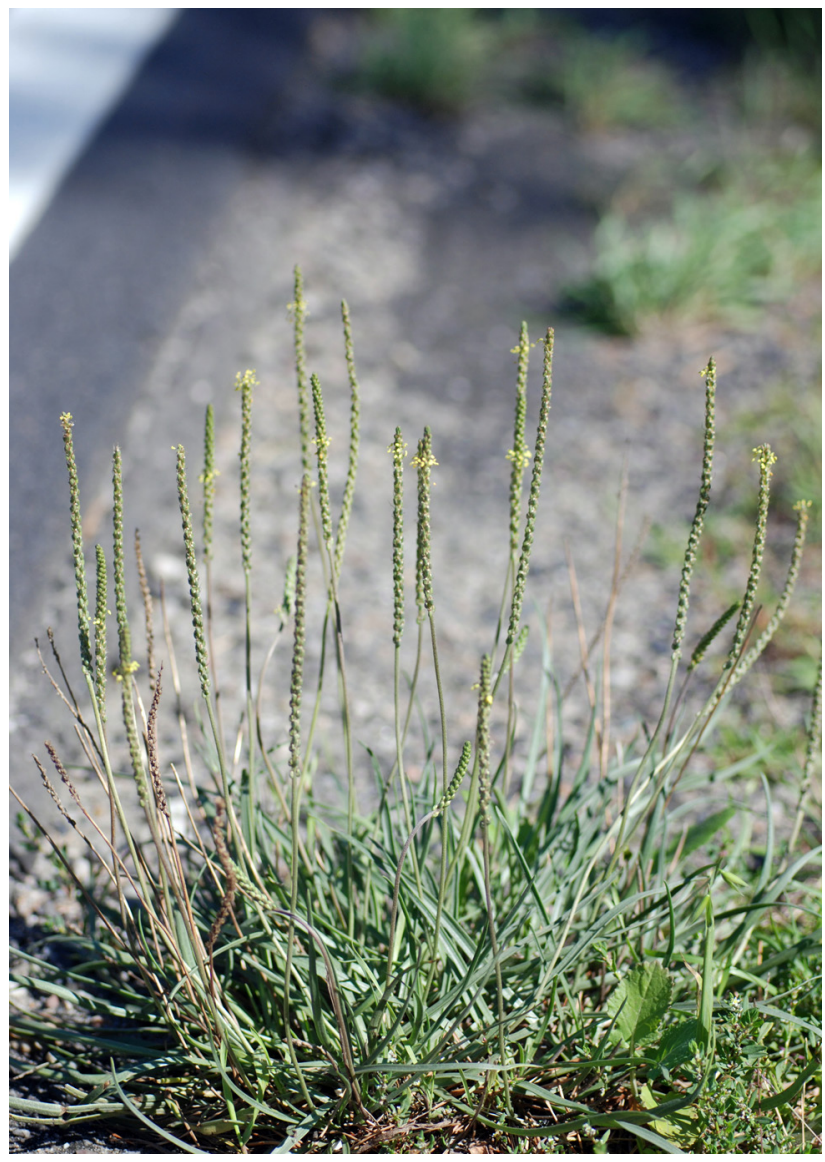

Ryc. 1. Widok na kępę Plantago maritima na poboczu szosy z Nowogrodu Bobrzańskiego do Zielonej Góry (20.08.2013 r., fot. A. Czarna)

Fig. 1. View of a clump of Plantago maritima, near the road from Nowogród Bobrzański to Zielona Góra (20.08.2013, photo by A. Czarna)

Można przypuszczać, iż w Polsce jest więcej tego typu stanowisk $P$. maritima. Takson ten powiększył liczbę gatunków zawlekanych z solą do posypywania dróg. Wcześniej podawany był P. coronopus z Poznania (Sотек 2014), a także bardzo rozpowszechniona obecnie w Polsce trawa Puccinellia distans, czy też Spergularia salina (własne obserwacje).

Stanowisko antropogeniczne $P$. maritima, które znajdowało się na poboczu szosy, było bardzo mocno zagrożone i w żaden sposób nie mogło być chronione.

\section{PODZIĘKOWANIA}

Populację Plantago maritima znaleziono w terenie podczas przemieszczania się z jednego starego cmentarza na drugi, w czasie realizacji grantu NCN 304204937.

\section{LITERATURA}

Ascherson P., Graebner P. (1898-1902): Synopsis der Mitteleuropäischen Flora 2(1). Verlag W. Engelmann, Leipzig.

FieK F. (1881): Flora von Schlesien praussischen und österreichischen Antheils, enthaltend die wildwaschsenden, verwilderten und angebauten Phanerogamen und Gefäss-Cryptogamen. J.U. Kern's Verlag, Breslau.

Jaźwia M., Piątek K. (2015): Nowe stanowiska rzadkich roślin naczyniowych na Pogórzu Ciężkowickim, Pogórzu Strzyżowskim i w Dołach Jasielsko-Sanockich (Karpaty Zachodnie). Fragmenta Floristica et Geobotanica Polonica 12(1): 100103.

Kaźmierczakowa R., Bloch-Orłowska J., Celka Z., Cwener A., Dajdok Z., Michalska-Hejduk D., Pawlikowski P., Szcześniak E., Ziarnek K. (2016): Polska czerwona lista paprotników i roślin kwiatowych. Polish red list of pteridophytes and flowering plants. Instytut Ochrony Przyrody PAN, Kraków.

Meusel H., JäGer E.J. (1992): Vergleichende chorologie der Zentraleuropäischen Flora. Bd. III. Fischer Verlag, Jena, Stuttgart, New York.

RozPORZĄDZENIE Ministra Środowiska z dnia 9 października 2014 r. w sprawie ochrony gatunkowej roślin. (2014). Dz.U. 2014, poz. 1409.

Sотек Z. (2014): Plantago coronopus L. Babka pierzasta. W: R. Kaźmierczakowa, K. Zarzycki, Z. Mirek (red.). Polska czerwona księga roślin. Instytut Ochrony Przyrody PAN, Kraków: 485-487.

Sotek Z., Prajs B., BiateckA B. (2014): Plantago maritima L. Babka nadmorska. W: R. Kaźmierczakowa, K. Zarzycki, Z. Mirek (red.). Polska czerwona księga roślin. Instytut Ochrony Przyrody PAN, Kraków: 487-489.

Szafer W., KulczyŃski S., Pawłowski B. (1986): Rośliny polskie. PWN, Warszawa. 